\title{
Le maoïsme de Tel Quel autour de Mai 68
}

\section{Kefei XU}

\section{(2) OpenEdition Journals}

Édition électronique

URL : http://journals.openedition.org/transtexts/436

DOI : $10.4000 /$ transtexts.436

ISSN : 2105-2549

\section{Éditeur}

Gregory B. Lee

\section{Édition imprimée}

Date de publication : 7 avril 2011

ISSN : 1771-2084

Référence électronique

Kefei XU, «Le maoïsme de Tel Quel autour de Mai 68 », Transtext(e)s Transcultures 跨文本跨文化 [En ligne], 6 | 2011, mis en ligne le 08 mars 2012, consulté le 01 mai 2019. URL : http:// journals.openedition.org/transtexts/436 ; DOI : 10.4000/transtexts.436 


\title{
Transtext(e)s
}

Transcultures 跨文本跨

文化

Journal of Global Cultural Studies

6 | 2011 :

Debating China

\section{Le maoïsme de Tel Quel autour de Mai 68}

\author{
KEFEI AU
}

\section{Résumé}

Le maoïsme de Tel Quel est un événement important de Mai 68, et c'est est un phénomène intéressant et significatif pour réfléchir sur les rapports entre les intellectuels et la politique. Séduits par la Révolution culturelle du fait de leur dévouement pour les révoltes contre tout genre de bureaucratisation, les maoïstes de Tel Quel considèrent le Maoïsme comme le sommet du marxisme, et mobilisent la culture chinoise ancienne dans leur mouvement d'avant-garde, afin de réaliser leur propre révolution culturelle en France. Cependant, la Chine dans le maoïsme de Tel Quel est une Chine imaginée, et au travers de cet imaginaire, il apparaît que c'est toujours la manière d'envisager une relation à l'autre qui pose problème.

\section{Texte intégral}

Comme revue d'écrivains et d'intellectuels d'avant-garde, Tel Quel est une revue qui prône une certaine forme d'engagement politique. ${ }^{1}$ Le maoïsme est ainsi le sommet de l'engagement politique de Tel Quel.

2 À l'automne 1966, juste après la déclaration de la Révolution culturelle en Chine, un cercle maoïste du nom de « Comité politique » se constitue autour de Philippe Sollers et des jeunes intellectuels proches de Tel Quel. En 1972, la revue se rallie alors ouvertement aux idéologies maoïstes après avoir rompu avec le Parti Communiste Français (PCF). ${ }^{2}$ En 1976, le maoïsme de Tel Quel perdurera après la mort de Mao. ${ }^{3}$ Pendant cette période maoïste, on peut noter 
trois événements principaux et déterminants de l'engagement politique de Tel Quel. Tout d'abord, en 1971, les maoïstes de Tel Quel se lancent dans le " mouvement de juin ». Brandissant la pensée Mao Zedong comme arme essentielle de combat idéologique et politique, les maoïstes de Tel Quel font leur Révolution culturelle sur tous les fronts. ${ }^{4}$ Ensuite, en 1972, Tel Quel publie des numéros consacrés à la Chine dans les revues 48 et $49 .^{5}$ Enfin, du 11 avril au 3 mai 1974, une délégation de Tel Quel se rend en voyage officiel en Chine. Le groupe est composé de cinq membres : Philippe Sollers, Julia Kristeva, Marcelin Pleynet, François Wahl et Roland Barthes. Les maoïstes de Tel Quel souhaitent observer la Révolution culturelle chinoise sur le terrain. En 1974, un autre numéro spécial sort au retour de leur voyage $\left(n^{\circ} 59,1974\right)$. Ce numéro est consacré à l'analyse de la Révolution culturelle.

3 Aujourd'hui, le maoïsme de Tel Quel nous parait lointain avec le changement de climat politique et intellectuel, mais il s'agit d'un exemple éclairant pour qui souhaite réfléchir sur le rôle de l'intellectuel. Comme phénomène transculturel, la recherche du maoïsme par Tel Quel nous montre la possibilité et la nécessité d'envisager autrement la relation avec l'Autre.

\section{Le maoïsme de Tel Quel et le marxisme}

Les maoïstes de Tel Quel ont toujours considéré le maoïsme dans le cadre du marxisme. C'est en se passionnant pour le marxisme dès les années 1960 que les « telqueliens » ont découvert le maoïsme. Ils voient en Mao la réincarnation de Lénine, et le maoïsme doit donc se situer à la tête des différents courants marxistes. Ce qui les intéresse dans le marxisme, c'est la question du matérialisme dialectique, une question développée par Mao dans son article " De la contradiction », un concept par ailleurs fondamental dans le matérialisme dialectique de Lénine. ${ }^{6}$ À l'instar de Mao, les maoïstes de Tel Quel récupèrent donc l'âme vivante du marxisme - le matérialisme dialectique. Mao devient à leurs yeux le plus grand maître marxiste après Marx, Engels et Lénine. Le maoïsme est ainsi considéré comme le sommet du marxisme des maoïstes de Tel Quel.

5 Selon les maoïstes de Tel Quel, le matérialisme dialectique de Mao est un remède contre « le dogmatisme et le révisionnisme » dérivant du marxisme orthodoxe. ${ }^{7}$ Lorsque Khrouchtchev accède à la tête de l'URSS, il applique une politique de déstalinisation en annonçant une coexistence pacifique avec l’impérialisme des États-Unis. Pour les maoïstes de Tel Quel, cette nouvelle voie de l'impérialisme social soviétique trahit le marxisme-léninisme. Mao pense alors que l'Union soviétique dérive de plus en plus de son sens originel en empruntant une ligne révisionniste, ce qui le poussera à rompre avec son ancien allié. La Chine devient dès lors le nouveau centre de l'action révolutionnaire mondiale, et les maoïstes de Tel Quel s'engagent alors ouvertement dans une valorisation des idées de Mao. Le courant chinois occupe une place prédominante au sein du courant marxiste mondial. En choisissant cette voie, les maoïstes de Tel Quel veulent lutter contre le dogmatico-révisionnisme du PCF qui soutenait la politique de l'Union soviétique dans les années 1960. Pour eux, le maoïsme devient le seul moyen 
de vaincre le dogmatisme et le révisionnisme.

De fait, pour les maoïstes de Tel Quel, le maoïsme est une idéologie plus affirmée pour la révolte que ne peut l'être la philosophie. Les maoïstes de Tel Quel sont des écrivains d'avant-garde avant d'être des philosophes marxistes. Ils rêvent d'une révolution esthétique et politique, et c'est pourquoi la Révolution culturelle chinoise les séduit. ${ }^{8}$ Les maoïstes de Tel Quel portent tout leur espoir sur la base théorique de la Révolution chinoise car le maoïsme est selon eux à la fois une idéologie révolutionnaire et une philosophie servant à dompter le système capitalisme.

7 Pourtant, à la suite de son désengagement du courant maoïste, Philippe Sollers, le premier des maoïstes de Tel Quel, considère que Mao a finalement « tué le marxisme ».

On peut dire peut-être que Mao Zedong a tué le marxisme. (...) La vraie interprétation, peut-être, de Mao, c'est d'avoir poussé le marxisme à son point d'incandescence pour le supprimer. ${ }^{9}$

Deux questions se posent donc : le maoïsme est-il le sommet du marxisme ? Et d'une autre manière, le maoïsme a t-il liquidé le marxisme ? Et pourquoi ces deux opinions contradictoires coexistent-elles dans l'histoire de l'évolution du maoïsme de Tel Quel ? Avant de répondre à ces questions, il est nécessaire d'en soulever de nouvelles. Qu'est-ce que le marxisme ? Plus précisément, qu'est-ce que le marxisme de Tel Quel, et qu'est-ce que le marxisme de Mao?

$9 \quad$ Les maoïstes de Tel Quel et Mao lui-même ont tous accepté le schéma marxiste de l'Histoire universelle, mais le marxisme de Tel Quel est un mélange de matérialisme, de structuralisme, de lacanisme, et d'autres courants philosophiques, quand le marxisme de Mao est une « sinisation » de la théorie de Marx qui intègre également des pensées chinoises traditionnelles, la dialectique du taoïsme par exemple. Et de là est né le conflit d'interprétation du marxisme originel entre Mao et les «telqueliens » maoïstes. Et c'est probablement ce qui explique que Philippe Sollers trouve, après son expérience maoïste en France, des divergences entre l'interprétation marxiste de Mao et sa propre compréhension du marxisme, et affirme que Mao aurait «tué » le marxisme originel, ou du moins ce qu'il croit et théorise du concept originel développé par Karl Marx.

\section{Le maoïsme de Tel Quel et l'anti- bureaucratisme}

La bureaucratie est un phénomène moderne mis en place dans toutes les formes d'organisation administrative et politique. Dans le sens courant, la bureaucratie désigne souvent le régime politique de l'Union Soviétique où la hiérarchisation de la bureaucratie est déléguée au service d'une couche dirigeante. En France, la bureaucratisation se propage également rapidement dans le camp de la gauche politique, principalement chez les communistes. Alors qu'il peine à poursuivre ses objectifs révolutionnaires depuis la fin de la Seconde guerre mondiale, le PCF ne cesse de dériver d'un parti révolutionnaire à un parti de l'ordre régalien, d'autant plus que le PCF demeure directement lié et inconditionnellement inféodé à l'URSS. Au début des événements de Mai 68, 
le PCF est ainsi hostile au mouvement étudiant. Pour la jeune génération, le PCF se dévalorise aux côtés du président De Gaulle et devant la bureaucratisation de l'URSS. Mais la menace de la bureaucratisation n'inquiète pas seulement l'URSS et la France, elle inquiète également la Chine populaire. Mao considère que les cadres du Parti Communiste ont perdu l'esprit révolutionnaire, et sont corrompus par le pouvoir et "infectés » par le " révisionnisme » soviétique. En 1966, Mao décide de lancer la Révolution culturelle et de balayer les bureaucrates de la sphère du pouvoir.

Les maoïstes de Tel Quel sont séduits par la Révolution culturelle du fait de leur dévouement pour les résistances et les révoltes contre tout genre de bureaucratisation. "Je m'étais mis en tête de cultiver très rapidement des gens qui étaient responsables de cette insurrection de 68, c'est-à-dire de les sortir un peu de leurs habitudes stéréotypées » dira en ce sens Philippe Sollers. ${ }^{10}$ Les « telqueliens » sont donc fascinés par la Révolution culturelle chinoise. A leurs yeux, Mao a tenté de trouver des solutions pour dépasser le phénomène de bureaucratisation, et par la Révolution culturelle, la Chine est devenue, selon eux, un pays idéal dépourvu de bureaucratisation.

12 Mao invente une nouvelle voie pour la démocratie : le dazibao (大字报). Pendant la Révolution culturelle, par le biais du dazibao, chacun est en droit de publier ses opinions politiques ou d'attaquer toute forme d'autorité. On confie aux femmes des positions politiques et sociales importantes : les femmes 《 conquièrent ainsi la moitié du ciel »(妇女能顶半边天 funü neng ding banbiantian), et la parité est alors en vigueur. Dans le domaine culturel, le confucianisme est aussi en ligne de mire car le confucianisme est à la racine d'un système social hiérarchisé. Enfin, la révolution de l'éducation en Chine, par le biais des écoles « à portes ouvertes » (开门办大学 kaimen ban daxue), brise les universités traditionnelles. Toutes ces mesures adoptées par Mao touchent les maoïstes de Tel Quel qui rêvent de changer de la même façon la société bureaucratique française.

13 Cependant, et avant même la dissolution officielle de Tel Quel, certains maoïstes « telqueliens » commencent à douter de l'anti-bureaucratisme de la Révolution culturelle. Pendant son séjour en Chine en 1974, Marcelin Pleynet désapprouve fortement les stéréotypes officiels qui leur sont judicieusement présentés par le pouvoir chinois. Cette visite exclusivement orientée est pour lui une " visite standard ». François Wahl, un des autres membres ayant effectué le voyage en Chine, publie lui dans Le Monde une série d'articles intitulée " La Chine sans utopie », du 15 au 19 juin 1974. Dans ces articles, le sentiment principal de Wahl est la déception. Aux yeux de Wahl, la Chine «s'est radicalement détachée du modèle soviétique ».

Le problème fondamental -- pour les Chinois et pour le monde entier -est de savoir si, pour et par la réussite ainsi obtenue, la Chine s'est radicalement détachée du modèle soviétique (..... ${ }^{11}$ l'anti-bureaucratisation de la Révolution culturelle chinoise ? Cette question complexe peut se développer sous deux aspects.

15 Tout d'abord, d'un point de vue sociologique, cette contradiction s'explique par la relation entre bureaucratisation et modernité. De fait, la bureaucratisation est un accompagnement de la modernité. D'un coté, le système bureaucratique est nécessaire, car la division des taches résulte d'une 
spécialisation des fonctions. De l'autre, la bureaucratie influe pour rendre l'organisation inefficace et tend à aliéner les hommes en raison de son recours à un système de hiérarchie entre supérieurs et subordonnés. Mao veut éradiquer la bureaucratie. Mais il souhaite en même temps poursuivre la modernisation. C'est un paradoxe sans solution.

16 Ensuite, la bureaucratisation visée par Mao et celle visée par les maoïstes de Tel Quel sont différentes. Mao critique les déviances de la bureaucratie, c'est à dire l'oppression et la corruption qui, selon lui, mettent en danger toute forme d'organisation du pouvoir, que cela soit le pouvoir dynastique ou un forme d'organisation du pouvoir transitoire et instable tel que le communisme récemment mis en place dans la Chine maoïste. En ce sens, Mao porte une réflexion sur les dérives de la bureaucratie traditionnelle ou pré-moderne, car, contrairement à la bureaucratisation moderne française ou soviétique, celle du modèle chinois n'en est encore qu'au stade primaire de développement, ce qui favorise les abus de pouvoir. Par contre, les maoïstes de Tel Quel focalisent eux leur critique sur l'effet aliénant de toutes formes de bureaucraties, qu'elle soient juvéniles ou modernes et stables comme le sont les bureaucraties française et stalinienne. Autrement dit, Mao met en avant le modèle d'une société égalitaire, vidée de toute oppression bureaucratique, tandis que les maoïstes de Tel Quel revendiquent la libération totale de toute aliénation bureaucratique. Il existe donc une incompréhension historique entre les maoïstes de Tel Quel et Mao lui-même.

\section{Le maoïsme de Tel Quel et la culture chinoise (classique)}

Les maoïstes de Tel Quel n'ont jamais cessé d'être fascinés par la culture chinoise (classique). ${ }^{12}$ Les intérêts des " telqueliens » concernant l'ancienne culture chinoise commencent bien avant leur époque maoïste. Certains anciens maoïstes de Tel Quel, comme Philippe Sollers, conservent d'ailleurs jusqu'à aujourd'hui une réelle fascination pour la culture chinoise.

Pour les maoïstes de Tel Quel, la culture chinoise fait partie de leur avantgarde, en ce sens qu'ils mobilisent souvent la culture pour la mettre au service d'une révolution aussi bien esthétique que politique. La fascination pour la culture chinoise des « telqueliens » se divise en trois étapes.

Avant le ralliement au maoïsme, la fascination pour la culture chinoise est plus esthétique que politique. De sa fondation au ralliement au maoïsme (officiellement en 1971), Tel Quel n'est pas une revue d'engagement politique, et les écrivains de Tel Quel utilisent tout d'abord la culture chinoise pour soutenir les révoltes esthétiques. Pour les « telqueliens », la culture chinoise, tout comme la littérature des écrivains marginaux, est une sorte de nouvelle ressource littéraire et intellectuelle s'opposant aux écrivains renommés (Jean-Paul Sartre par exemple). Philippe Sollers et Marcelin Pleynet ont respectivement écrit des " romans chinois », c'est à dire des romans d'avant-garde utilisant la culture chinoise. ${ }^{13}$ Aux yeux des "telqueliens », la culture chinoise est équivalente à la culture de la Grèce antique à la Renaissance. Toutefois, nous pouvons constater que la culture chinoise est progressivement politisée par les «telqueliens », jusqu'à leur ralliement au 
maoïsme.

Pendant l'époque maoïste de Tel Quel, la fascination pour la culture chinoise est plus politique qu'esthétique. Du fait de la politisation de Tel Quel, l'esthétique avant-gardiste va rapidement se trouver occultée par la «folie » politique. Au même titre que la Révolution culturelle de Mao, la « révolution » politique tout autant qu'esthétique de Tel Quel concerne également le domaine culturel, et la culture chinoise en fait partie. La révolution culturelle des maoïstes de Tel Quel explique tout autant qu'elle s'étend à leur fascination de la culture chinoise, et pour les "telqueliens ", la connaissance de la culture chinoise a d'abord pour but de mieux comprendre la Révolution culturelle chinoise. Ainsi, la fascination pour la culture chinoise est aussi politisée et intégrée dans leur volonté de mener leur propre " révolution » culturelle en France.

21 Néanmoins, après leur désillusion du maoïsme, la fascination pour la culture chinoise prend la voie d'un questionnement sur l'esthétique, l'ambition des « telqueliens » (ou des anciens « telqueliens ») pour une révolution politique se trouvant compromise. ${ }^{14}$ Certains des anciens maoïstes comme Philippe Sollers se convertissent au Taoïsme (道家 Daojia) et recherchent de nouvelles croyances. Leur déception intensifie leurs actes de négation de tout engagement intellectuel. En conséquence, ils se retrouvent rapidement confrontés au problème du nihilisme, bien que le déroulement du Dao puisse justement se poser comme un remède au nihilisme causé par l'avant-gardisme.

En parallèle à une politisation de la culture chinoise à travers l'idéologie maoïste, les " telqueliens » ont surtout découvert la pensée chinoise par le maoïsme. Pour eux, Mao a pénétré le panthéon du marxisme avec Marx, Engels et Lénine, mais en même temps, la pensée de Mao Zedong puise également dans les sources de l'histoire chinoise. Car Mao est en effet fortement influencé par la philosophie chinoise, et le maoïsme diffère des autres courants marxistes sur deux points primordiaux : le non-déterminisme et le volontarisme. Ces points sont tous deux hérités de la tradition chinoise. Par son influence, le taoïsme a donné au maoïsme un corps plus flexible que le déterminisme du marxisme orthodoxe. ${ }^{15}$ Quant au volontarisme de Mao, il provient des enseignements $\mathrm{du}$ néoconfucianisme qui en partie insiste sur l'idée que l'« être » est compris dans le cœur. ${ }^{16}$ Pour les maoïstes, la philosophie chinoise a fait resurgir la problématique de la dialectique matérialiste de son " hégélianisme ». Par les lectures du matérialisme dialectique de Mao, les maoïstes de Tel Quel s'identifient à la philosophie chinoise.

\section{Le maoïsme de Tel Quel comme imaginaire}

23 On pose souvent la même question aux maoïstes de Tel Quel : pourquoi la Chine ? Cette question hante également les anciens maoïstes de Tel Quel, par exemple quand Marcelin Pleynet admet que le maoïsme occidental est une sorte d' ' introjection ». ${ }^{17}$ Le maoïsme de Tel quel veut chercher la solution du « dehors » (la Chine maoïste) pour conquérir les problèmes du « dedans » (en France). C'est-à-dire que même si le maoïsme de Tel Quel est un phénomène issu de la Chine maoïste, il émane surtout d'un contexte spécifiquement 
français en vue de résoudre des problèmes sociaux spécifiques à la société française. De fait, pour les maoïstes « telqueliens », la Chine devient un miroir inversé du modèle social français où il existe toutes les maladies graves de l'aliénation de la modernité. Lucien Bianco fait d'ailleurs la remarque suivante en parlant du phénomène maoïste en France :

C'est que la Chine était une solution à leurs problèmes, à nos problèmes de français et occidentaux ou de révolutionnaires occidentaux dans le monde occidental. La Chine ne les intéressait pas en soi ; la Chine était un prétexte, et jamais il n'y avait la question : est-ce que le maoïsme est adapté aux problèmes de la Chine et en particulier à ceux auxquels elle doit s'attaquer de toute urgence. ${ }^{18}$

En conséquence, l'introjection de la Chine en France est surtout une représentation imaginaire. Le discours des maoïstes de Tel Quel ne se pose pas la question de ce qui s'est passé pendant la Révolution culturelle chinoise. Le milliard de Chinois ne compte pas pour beaucoup des maoïstes de Tel Quel. La Chine est ainsi représentée à travers un filtre de convenance qui obstrue la vision de toute réalité sociale et historique. Pour les maoïstes de Tel Quel, la Chine est évidement mythifiée, et les maoïstes de Tel Quel sont eux mythifiants.

La Chine dans l'imaginaire des maoïstes de Tel Quel fonctionne comme un Autre, et les maoïstes de Tel Quel sont tombés, eux aussi, dans le piège de l'ethnocentrisme. Pleynet a d'ailleurs fait son autocritique sur l'introjection du maoïsme. Selon lui, cette introjection était une erreur, au même titre que la projection du droitisme.

\begin{abstract}
Chacun de ces discours est à mon avis à lire comme le symptôme d'une maladie qui ne dirait jamais son nom. Dans la projection paranoïaque, dans l'injection anxieuse dira-t-on, soit la tentative de se convaincre que l'appareil de classe ne saurait disparaitre, et la meilleure façon de s'en convaincre c'est encore de projeter ses propres fantasmes de pouvoir sur l'autre, soit la tentative de combler le manque, l'absence d'appareil, par un appareil idéal (c'est-à-dire construit sur des modèles connus) et lointain auquel s'identifier. ${ }^{19}$
\end{abstract}

La maladie commune à l'introjection des maoïstes et la projection dont parle Pleynet peut être nommée ethnocentrisme, car la Chine dans l'imaginaire n'était qu'un objet du message. Et les destinataires du message étaient les maoïstes « telqueliens » en Occident. Marcelin Pleynet aperçoit l'ethnocentrisme dans l'introjection du maoïsme, même s'il ne trouve pas le chemin pour en sortir.

Par ailleurs, et ironiquement, les maoïstes de Tel Quel ont amputé une partie de la pensée de Mao. En plus de « De la contradiction », Mao a écrit a un autre article philosophique qui nous intéresse en particulier, il s'agit de «De la pratique ». Le sous-titre de " De la pratique » de Mao est « La relation entre la connaissance et la pratique - le savoir et l'action », et dans son article, Mao avance son opinion sur ce sujet. Pour lui, la connaissance dépend de la pratique sociale. Visant le subjectivisme et le dogmatisme, Mao souligne le savoir par la pratique.

你要有知识, 你就得参加变革现实的实践。你要知道梨子的滋味, 你就得 变革梨子, 亲口吃一吃。

Si l'on veut acquérir des connaissances, il faut prendre part à la pratique 
qui transforme la réalité. Si l'on veut connaître le goût d'une poire, il faut la transformer : en la goûtant. ${ }^{20}$ l'importance à « De la pratique ». Et ils n'ont quasiment jamais gouté la « poire » en Chine. Et pour sortir de l'ethnocentrisme de cet imaginaire, le remède apparaît finalement encore plus simple et plus clair : aller voir la réalité telle qu'elle est, ou telle qu'elle était, en Chine.

\section{Notes}

1 Tel Quel (1960-1982) est une revue de littérature d'avant-garde publiée dès la fin des années 1950 par Philippe Sollers et Jean-Edern Haillier. Dans une France alors en pleine restructuration sociale, le but de cette entreprise est de créer une plateforme de diffusion de nouvelles idées, en ayant recours pour cela à la littérature.

2 En 1971, le comité décisionnel reçoit par hasard le manuscrit « De la chine » de Maria-Antoinette Macciocchi (1922-2007, membre du Parti Communiste Italien). Alors que le PCF prohibe la circulation de cet ouvrage aux fêtes annuelles du parti, Tel Quel s'oppose à cette censure et rompt avec le PCF en 1972. La revue se rallie alors ouvertement aux idéologies maoïstes.

3 En 1976, Tel Quel publiait «A propos du 'maoïsme'» : « (...) précisons donc que si Tel Quel a en effet, pendant un certain temps, tenté d'informer l'opinion sur la Chine, surtout pour s'opposer aux déformations systématiques du PCF, il ne saurait en être de même aujourd'hui. Cela fait longtemps, d'ailleurs, que notre revue est l'objet d'attaque de la part des « vrais maoïstes » (...), il faut en finir avec les mythes, tous les mythes. » (Tel Quel, «A propos du maoïsme », Tel Quel, n68, 1976, p.104).

4 Selon les maoïstes de Tel Quel, le mouvement de juin 1971 est né d'une révolte interne à Tel Quel, contre la ligne droitière et révisionniste.

5 Dans ces deux numéros, la moitié des articles analysent la pensée et la culture chinoises. Pour le reste, on y trouve des descriptions favorables à la Chine révolutionnaire dans le but de critiquer le PCF. Grâce à ces deux numéros, Tel Quel connaîtra des records de ventes (de 20000 à 25000 exemplaires).

6 « De la contradiction » (août 1937) et « De la pratique » (juillet 1937), fonctionnent comme les pivots de la pensée de Mao Zedong. Ces deux essais furent importants pour asseoir la crédibilité de Mao comme théoricien, et renforcer ainsi sa prétention à diriger le parti. Aux yeux des maoïstes occidentaux, ces deux articles ont développé le matérialisme dialectique à un niveau plus élevé. Et par ces articles philosophiques, Mao est apparu comme un nouveau leader du marxisme.

7 Selon les les maoïstes de Tel Quel, le couple « dogmatisme et révisionnisme » se combine en dogmatico-révisionnisme.

8 Bien que Mao affirme, comme la plupart des marxistes, que la transformation des infrastructures s'accompagne d'une large transformation des superstructures, il soutient également que la transformation des superstructures peut entraîner à son tour une réinitialisation des infrastructures.

9 Philippe Sollers, « Pourquoi j'ai été chinois », Tel Quel, nº88, été 1981, p.12.

10 Philippe Sollers, « Pourquoi j'ai été chinois », Tel Quel, n88, été 1981, p.13.

11 François Wahl, « La Chine sans utopie II : Tien an men ou de l'explication avec le modèle soviétique ? ", Le Monde, 16 juin 1974.

12 Chez les (anciens) maoïstes de Tel Quel, l'expression « culture chinoise » signifie la culture chinoise ancienne (esthétique) et non la culture révolutionnaire moderne chinoise (politique). Par exemple, le yangbanxi 样板戏 (opéra de Pékin révolutionnaire) n'est pas compris dans la « culture chinoise ». Dans cet article, on suivra la conception de la « culture chinoise » de Tel Quel.

13 Les deux « romans chinois » les plus connus de Philippe Sollers sont Drame (1965) et Nombre (1968). Dans ces deux " romans chinois », Philippe Sollers prend pour référence le Yi-Jing 易经 (Classique des mutations). Le roman chinois de Marcelin 
Pleynet est Stanze IV, qui emprunte une légende - Bande d'or - à un roman chinois très populaire, le Xiyouji 西游记 (Voyage en Occident).

14 La révolution esthétique se retrouvera par la suite dans la même posture.

15 On peut remarquer que la pensée de Mao Zedong a transporté au sein de la société la dialectique du Yin et du Yang, originellement un système d'explication des antagonismes de la nature. Pour Mao, le principe de l'interdépendance des adversaires est par exemple au centre de la théorie maoïste de la contradiction. " C'est ce qui se produit avec tous les opposés ; dans certaines conditions ils sont opposés entre eux, dans d'autres ils sont réciproquement reliés : ils se complètent, ils sont perméables réciproquement, ils sont interdépendants ; c'est ce que nous appelons identité » (Mao Zedong, « De la contradiction », http://classiques.chez-alice.fr/mao/contradic1.html, dernière consultation le 12 février 2012). Dans le taoïsme, l'action permanente des contraires donne lieu à la complémentarité. "Ayant et n'ayant pas naissent l'un de l'autre, compact et subtil se forment l'un de l'autre, long et court se disent l'un par rapport à l'autre, haut et bas se tournent l'un vers l'autre, notes et sons s'accordent les uns avec les autres, avant et après se suivent l'un l'autre. " (Lao zi, Dao De Jing : Le livre de la Voie et de la Vertu, trad. du chinois par Claude Larre, Paris, Desclée de Brouwer, 2002, p 29).

16 Avant de se plonger dans le marxisme, Mao était un disciple du Xinxue, une branche du néoconfucianisme. Un essai du jeune Mao intitulé « La puissance de l'esprit » (心之 力 xin zhi li) indique que le volontarisme du Xinxue est profondément ancré dans la mentalité de Mao : "Les hommes ne sont point les esclaves de la réalité objective. Pourvu seulement que la conscience des hommes soit en conformité avec les lois objectives du développement des choses, l'activité subjective des masses populaires peut se manifester dans une pleine mesure, surmonter toutes les difficultés, créer les conditions nécessaires et faire avancer la révolution. Dans ce sens, le subjectif crée l'objectif. » (Stuart Schram, Mao Tsé-toung, Paris, Armand Colin, 1963, p.87).

17 Après réflexion, Marcelin Pleynet fait un bilan des diverses réponses à cette question «Pourquoi la Chine ? ». Pour lui, la plupart de ces réponses fonctionnent soit comme introjection - « le sujet fait passer, sous un mode fantasmatique, du « dehors » au « dedans » des objets et des qualités inhérents à ces objets », soit comme projection « opération par laquelle un fait neurologique ou psychologique est déplacé et localisé à l'extérieur, soit en passant du centre à la périphérie, soit du sujet à l'objet. » (Marcelin Pleynet, « Du discours sur la Chine », Tel Quel, n60, 1974, p.12). Après ce bilan, il admettra que le maoïsme occidental est une sorte d' « introjection ».

18 Lucien Bianco, «La Chine à la française », Matériaux pour l'histoire de notre temps, janvier-mars 1987, p.36.

19 Marcelin Pleynet, « Du discours sur la Chine », Tel Quel, n60, 1974, p12.

20 Mao Zedong, " De la pratique », http://classiques.chez-alice.fr /mao/delapratique.html, dernière consultation le 12 février 2012.

\section{Pour citer cet article}

Référence électronique

Kefei XU, «Le maoïsme de Tel Quel autour de Mai 68 », Transtext(e)s Transcultures 跨 文本跨文化 [En ligne], 6 | 2011, mis en ligne le 08 mars 2012, consulté le 08 mars 2012. URL : http://transtexts.revues.org/436

\section{Auteur}

\section{Kefei XU}

XU Kefei est maître de conférences à l'Université Normale de Pékin où il enseigne la philosophie contemporaine française. Docteur en études transculturelles, il est également spécialiste du mouvement intellectuel de Mai 1968.

\section{Droits d'auteur}


(C) Tous droits réservés 